\title{
Multimodal mechanosensing enables treefrog embryos to escape egg-predators
}

\author{
Authors: \\ Panamá \\ ${ }^{\mathrm{L}}$ Lead contact \\ *Author for correspondence (jungj@,bu.edu) \\ Contact info for corresponding author: \\ Julie Jung \\ Department of Biology \\ 5 Cummington Mall \\ Boston, MA \\ 02215 \\ (510) 439-7614 \\ jungj@,bu.edu
}

Julie Jung $^{1 * L}$, Shirley J. Serrano-Rojas ${ }^{2}$, Karen M. Warkentin ${ }^{1,2}$

${ }^{1}$ Department of Biology, Boston University, 5 Cummington Mall, Boston, MA, 02215, USA

${ }^{2}$ Smithsonian Tropical Research Institute, Apartado Postal 0843-03092, Panamá, República de

Key words: environmentally cued hatching, lateral line system, behavioral plasticity, biotremology, ontogeny, vestibular system.

Abbreviations: $\mathrm{MCH}$ - mechanosensory cued hatching; VOR - vestibulo-ocular reflex; 4-di-2ASP - 4-(4-diethylaminostyryl)-1-methylpyridinium iodide; CI - confidence interval; SEM standard error of the mean.

\section{SUMMARY}

Red-eyed treefrog embryos use both their lateral line and vestibular systems to sense the disturbance cues in egg-predator attacks that inform escape-hatching decisions. 


\begin{abstract}
Mechanosensory-cued hatching $(\mathrm{MCH})$ is widespread, diverse, and improves survival in many animals. From flatworms and insects to frogs and turtles, embryos use mechanosensory cues and signals to inform hatching timing, yet mechanisms mediating mechanosensing in ovo are largely unknown. The arboreal embryos of red-eyed treefrogs, Agalychnis callidryas, hatch prematurely to escape predation, cued by physical disturbance in snake attacks. When otoconial organs in the developing vestibular system become functional, this response strengthens, but its earlier occurrence indicates another sensor must contribute. Post-hatching, tadpoles use lateral line neuromasts to detect water motion. We ablated neuromast function with gentamicin to assess their role in $A$. callidryas' hatching response to disturbance. Prior to vestibular function, this nearly eliminated the hatching response to a complex simulated attack cue, egg-jiggling, revealing that neuromasts mediate early $\mathrm{MCH}$. Vestibular function onset increased hatching, independent of neuromast function, indicating young embryos use multiple mechanosensory systems. MCH increased developmentally. All older embryos hatched in response to eggjiggling, but neuromast function reduced response latency. In contrast, neuromast ablation had no effect on timing or level of hatching in motion-only vibration playbacks. It appears only a subset of egg-disturbance cues stimulate neuromasts; thus embryos in attacked clutches may receive uni- or multimodal stimuli. A. callidryas embryos have more neuromasts than described for any other species at hatching, suggesting precocious sensory development may facilitate $\mathrm{MCH}$. Our findings provide insight into the behavioral roles of two mechanosensory systems in ovo and open possibilities for exploring sensory perception across taxa in early life stages.
\end{abstract}




\section{INTRODUCTION}

3 Animals ubiquitously use vibration to inform their behavior (Cocroft et al., 2014; Hill et al.,

4 2019; Hill, 2009). Most research in this area focuses on vibrational communication signals in the

5 contexts of mate choice, competition, and parental care (Cocroft et al., 2014). These signals are

6 intentionally produced and generally operate between conspecifics. In addition, passively

7 produced, unintentional vibrational cues can inform behavior. A smaller subset of research

8 examines how animals use such incidental vibrations and other physical disturbance cues,

9 generated either abiotically or biotically, to express context-appropriate behaviors. Conspecifics

10 can generate disturbance cues (Doody et al., 2012), but other sources abound, such as weather

11 (Marquez et al. 2016) and, more commonly, predators and prey (Bacher et al., 1997; Brownell

12 and Leo van Hemmen, 2001; Castellanos and Barbosa, 2006; Oberst et al., 2017; Pfannenstiel et

13 al., 1995; Roberts, 2018). Physical disturbances generated incidentally as animals move might be

14 especially useful as cues because they can be difficult to conceal in a predator-prey context. Even

15 embryos can sample incidental disturbance cues from their environments (Warkentin 2005;

16 Warkentin, 2011a; Warkentin et al., In press). Like later life stages, embryos use physical

17 disturbance cues from abiotic sources such as rainfall (Roberts, 2001), or biotic sources such as

18 conspecifics (Endo et al., 2019; Noguera and Velando, 2019), hosts (Wang et al., 2012;

19 Whittington and Kearn, 1988; Whittington and Kearn, 2011), and predators (Doody and Paull,

20 2013; Warkentin, 2005). From flatworms and insects to frogs and turtles, embryos of all sorts use

21 disturbance cues to inform their hatching timing, yet the mechanisms mediating vibration and

22 other mechanosensing in ovo are largely unknown.

24 The red-eyed treefrog, Agalychnis callidryas, is an excellent species in which to study how

25 embryos detect and respond to physical disturbance or vibrations. As adults, these arboreal

26 amphibians lay eggs on plants overhanging rainforest ponds. Usually within seven days, embryos

27 hatch and fall into the water below, where they will develop as tadpoles, but they can hatch

28 prematurely to escape from threats to eggs, including pathogens, flooding, and terrestrial egg

29 predators (Warkentin and Caldwell, 2009). This escape-hatching response changes dramatically

30 over development. The earliest observed hatching occurs at 3 days post-oviposition in response

31 to strong hypoxia cues, but the onset of predator-induced, mechanosensory-cued hatching 
$32(\mathrm{MCH})$ does not occur until the following day (Warkentin et al., 2017). During the period of

33 development between the onset of hatching responses to hypoxia and to mechanosensory cues,

34 embryos are clearly able to hatch to escape threats. Nonetheless, they do not use this ability to

35 flee from predators. Hatching ability is, therefore, not the sole constraint limiting the onset of

36 escape-hatching responses to predator attacks.

The embryos of Agalychnis callidryas clearly use cues in multiple sensory modalities, including vibration (Warkentin 2005, Warkentin et al. 2019), hypoxia (Rogge and Warkentin, 2008) and light level (Güell and Warkentin, 2018), to inform hatching. In sensing physical disturbances, these embryos might use one or multiple mechanosensory systems, either to perceive different cue components available in attacks or as potentially redundant or synergistic sensors of the same cue component. As a first step toward determining the role of mechanosensory system development in the ontogeny of predator-induced hatching ability, we examined a general vertebrate motion sensor, the vestibular system of the inner ear (Jung et al., 2019). When otoconial organs in the developing vestibular system become functional, $\mathrm{MCH}$ increases substantially, but its earlier occurrence at a low level indicates that vestibular mechanoreceptors cannot be the only sensors that enable hatching when eggs are physically disturbed (Jung et al., 2019).

The mechanosensory lateral line system is found in all fishes and aquatic life stages of amphibians and serves to detect movement, vibrations, and pressure gradients in the surrounding water. It is comprised of mechanoreceptive neuromast sensory organs with hair cells that are sensitive to local water displacements (Lannoo, 1999) and are similar in morphology and function to hair cells in the auditory and vestibular system of vertebrates (Mogdans, 2019; Roberts et al., 1988). The lateral line system and vestibular system are responsive to many of the same stimulus fields (Braun and Coombs, 2000) and the hair cells of the lateral line and inner ear even have comparable thresholds of pressure detection (Van Netten, 2006). When something moves in the water, it creates water motion that deflects the ciliary bundles of the hair cells of the neuromasts, which opens mechanically gated ion channels (Harris et al., 1970; Sand et al., 1975).

61 This stimulus information is sent to the brain, helping fishes and aquatic amphibians orient in currents (Elepfandt, 1982; Montgomery et al., 1997), maintain position within a school 
63 (Partridge and Pitcher, 1980), find prey (Bleckmann, 1980; Hoekstra and Janssen, 1985;

64 Montgomery and Macdonald, 1987; Pohlmann et al., 2004), and detect predators (Montgomery,

65 1989; Schwalbe et al., 2012). Fishes and aquatic amphibians are able to detect low-level water

66 motion with both the lateral line system and the inner ear, but the relative roles of these sensory

67 systems is unclear (Karlsen and Sand, 1987).

Here we investigate the potential contribution of the embryonic lateral line system to sensing physical disturbance cues that inform escape-hatching decisions of $A$. callidryas embryos during snake attacks. When snakes bite, bump, and pull at eggs, embryos may receive complex mechanosensory stimuli, including motion, pressure, and tactile elements (Jung et al., 2019). The flow of perivitelline fluid, which constantly circulates around embryos, may also be altered as snakes stretch or squash egg capsules, thereby altering input to the lateral line system in the egg. However, not all embryos in an attacked clutch receive these complex cues. Embryos more distant from the snake may receive only whole-egg motion cues, transmitted through the clutch, but it is unclear if or how such whole-egg motion could stimulate the lateral line system (Jung et al., 2019). To assess the role of the lateral line and vestibular systems in sensing complex mechanosensory stimuli, we used a simulated attack cue (jiggling eggs in a standardized fashion with a blunt probe; Warkentin et al., 2017). We tested embryos with functional and inactivated lateral line systems, before and after the onset of vestibular function. To assess if egg motion alone stimulates the lateral line system, we used a custom-made vibration playback system to shake eggs in trays without providing concurrent tactile or egg deformation cues (Warkentin et al., In press; Warkentin et al., 2019) and tested embryos with functional and inactivated lateral line systems. Thus, we assessed the role of two mechanosensory systems, in two disturbance cue contexts, in a critical anti-predator behavior demonstrated by developing embryos.

\section{MATERIALS AND METHODS}

\section{Egg clutch collection and care}

We collected young (0-1 d old) A. callidryas egg clutches and the leaves on which they were laid from the Experimental Pond in Gamboa, Panama (9.120894 N, 79.704015 W) and brought them to a nearby laboratory (at ambient temperature and humidity) at the Smithsonian Tropical

95 Research Institute. We mounted clutches on plastic cards for support, positioned them over aged

96 tap water in plastic cups, then placed them inside plastic bins with screen lids connected to an 
automatic misting system (Mist King, Jungle Hobbies, www.mistking.com) set to mist clutches with rainwater at regular intervals to maintain hydration. Most clutches are laid between $10 \mathrm{pm}$ and $2 \mathrm{am}$, so we assigned embryos to daily age-classes and reported developmental timing starting from midnight of their oviposition night (Warkentin, 2002; Warkentin, 2005). All tested individuals were staged based on external morphological markers (Warkentin, 2017) and were morphologically normal, in developmental synchrony with siblings in their clutch, and in intact, turgid eggs at the start of experiments. Hatchlings from gentamicin-treated eggs were reared in the laboratory under ambient conditions until hair cells regenerated (Hernández et al., 2007; Ma et al., 2008; Thomas et al., 2015; Williams and Holder, 2000), within $3 \mathrm{~d}$ of hatching. All

106 hatchlings were returned to the pond from which they were collected. This research was conducted under permits from the Panamanian Environmental Ministry (SC/A-10-18 and SE/A42-19) and approved by the Institutional Animal Care and Use Committee of the Smithsonian Tropical Research Institute (2017-0601-2020-2).

\section{Vestibulo-ocular reflex (VOR) measurement}

To assess vestibular function, we measured roll-induced VOR of newly hatched tadpoles or manually decapsulated embryos using previously described methods (Horn and Sebastian, 1996; Horn et al., 1986; Jung et al., 2019). We placed hatchlings in a close-fitting tube of water and used a custom-made tadpole rotator to roll them about their body axis $180^{\circ}$ in each direction, photographing them in frontal view each $15^{\circ}$ (Jung et al., 2019). This method allowed us to measure vestibular function rapidly and without anesthesia. From each photograph, we measured right and left eye angle and body axis angle using ImageJ (Schneider et al., 2012). From each angular measurement series, we constructed an individual VOR curve using a sine-fitting function in Python (Version 2.7.9, Build 1, Python Software Foundation). The peak-to-peak amplitude of the curve fit is the measured VOR magnitude.

\section{Lateral line system visualization with 4 -di-2-ASP}

To visualize hair cells in neuromasts, newly hatched or decapsulated tadpoles were immersed in a $500 \mu \mathrm{M}$ solution of the fluorophore 4-(4-diethylaminostyryl)-1-methylpyridinium iodide (4-di2-ASP, Sigma D-3418, sigmaaldrich.com) for five minutes at room temperature in the dark. Tadpoles were then rinsed in aged tap water to remove excess fluorophore and placed in a shallow petri dish or snout-up in a modified pipette mount. This method allowed us to label neuromast hair cells and photograph them in live embryos without anesthesia or treatment with a paralytic. We used an Olympus stereoscope equipped with epifluorescence (GFP filter set) to photograph each individual._We considered neuromasts showing fluorescence to be functional and a complete lack of fluorescence to indicate neuromast inactivation. Fluorescence gradually faded within hours and disappeared within a day of treatment. Treated individuals developed normally compared to untreated controls.

\section{Lateral line system knockout with gentamicin}

To test the role of the lateral line system in predator-induced, mechanosensory-cued escapehatching behavior, we used the ototoxic aminoglycoside antibiotic gentamicin to ablate neuromast function (Kroese and van den Bercken, 1982; Montgomery et al., 1997; Van Trump et 
al., 2010). At embryonic age $3 \mathrm{~d}$, we removed individual eggs from clutches and placed groups of eight siblings into hexagonal polystyrene weigh boats $(4.5 \mathrm{~cm}$ across $\mathrm{x} 1 \mathrm{~cm}$ depth). We added $1 \mathrm{~mL}$ of rainwater to each boat, partially submerging eggs, and waited $1 \mathrm{~h}$ for water absorption to increase and standardize turgidity before treatment. To begin treatment, we removed the remaining water and added a fresh $1 \mathrm{~mL}$ of rainwater into each boat. Control eggs remained in rainwater, while treatment eggs received a timed dosage series of gentamicin sulphate solution10 (MP Biomedicals $^{\mathbf{T M}}$, fishersci.com) mixed into the rainwater to gradually increase the concentration (starting dose $2 \mu \mathrm{L},+2 \mu \mathrm{L}$ at $3 \mathrm{~h},+2 \mu \mathrm{L}$ at $6 \mathrm{~h},+0.5 \mu \mathrm{L}$ at $9 \mathrm{~h},+0.5 \mu \mathrm{L}$ at 10.5 h). The final concentration was the minimum dosage that effectively blocked lateral line system function, determined based on pilot experiments. The gradual increase in concentration was necessary to maintain egg turgor and membrane integrity, as needed for hatching assays, also based on pilot experiments. At $13 \mathrm{~h}$, we extracted $0.5 \mathrm{~mL}$ of solution from each boat to increase air exposure of eggs and ensure sufficient oxygen availability for these terrestrial eggs as they continued developing in the boats until hatching-response tests were carried out. Only eggs that maintained normal turgidity until testing were used to assess embryo responses to mechanosensory cues. We confirmed lateral line system blocking with 4-di-2-ASP staining in each experiment (Fig. 1A-B). To assess if gentamicin damaged hair cells in embryonic ears, as suggested previously (Bagger-Sjoback, 1997; Simmons et al., 2004; Van Trump et al., 2010; Yan et al., 1991), we compared VOR of stage-matched (within one developmental stage of each other) control and gentamicin-treated siblings, across all experiments described below (Fig. 1C).

\section{Hatching-response test: manual egg jiggling}

To assess the MCH response of gentamicin-treated (Fig. 1A) and control (Fig. 1B) embryos across ontogeny, we performed a standard egg-jiggling assay (simulated attack), using a blunt probe to manually jiggle eggs in an intermittent pattern for 5 min (Jung et al., 2019; Warkentin et al., 2017). This simulated attack includes complex motion and tactile elements, and transient deformation of egg membranes. We tested 1202 individual embryos from 60 clutches (at least 5 individuals per treatment per clutch) from July 2 to August 5, 2019. We moved sibling pairs of eggs (treatment and control individuals) into their own weigh boats with a drop of water and manually jiggled them with a blunt metal probe, alternating $15 \mathrm{~s}$ of stimulation and $15 \mathrm{~s}$ of rest (i.e., stimulating eggs in a pair alternately) for 5 minutes or until the embryo hatched.

We exposed embryos to jiggling cues during three developmental periods (Fig. 2A): (1) across the onset of vestibular function ( $\mathrm{N}=544$ individuals later subdivided based on VOR measurements; range, mean \pm SEM age: 4.03-4.36 d, $4.19 \pm 0.003 \mathrm{~d}$; stage 27-28, $27.19 \pm$ 0.017), (2) after vestibular function was well-established ( $\mathrm{N}=360$ individuals; 4.54-5.03 d, $4.74 \pm 0.007 \mathrm{~d}$; stage: $27-30,28.99 \pm 0.010)$, and (3) closer to spontaneous hatching $(\mathrm{N}=298$ individuals, age: $5.29-5.56 \mathrm{~d}, 5.39 \pm 0.003 \mathrm{~d}$, stage: $29-32,30.44 \pm 0.046)$. For the youngest age group, we measured the VOR of all individuals that hatched ( $\mathrm{N}=67$ individuals) and checked for lateral line system blocking of all hatched, gentamicin-treated individuals $(\mathrm{N}=3)$. We used VOR measurements to determine vestibular function onset times, dividing siblings into subsets tested before and after VOR onset. For the two older groups, we measured VOR in at least one 186 gentamicin-treated and one control individual per clutch ( $\mathrm{N}=111$ individuals). We used 4-di-2187 ASP staining to check for lateral line system blocking in at least one individual per gentamicin- 
treatment boat with hatching and visualized neuromasts in one untreated control per testing session (i.e., the period of hours over which a group of trays were tested; $N=31$ individuals).

For the youngest developmental period, we determined the start of testing for each sibship based on external developmental markers (Warkentin, 2017). We began testing early in stage 27, near the mean first appearance of MCH across clutches (Warkentin et al., 2017) and shortly before the onset of vestibular function (Jung et al., 2019), then stimulated pairs of siblings sequentially until VOR was visible in tested hatchlings. After analysis of VOR tests, we estimated the onset of vestibular function for each clutch as the first time point at which any individual from the clutch showed a VOR $>10^{\circ}$. Applying this criterion generated two groups: "no VOR" $(\mathrm{N}=286$ individuals; age 4.03-4.36, $4.17 \pm 0.005 \mathrm{~d}$; all stage 27$)$ and "with VOR" ( $\mathrm{N}=258$ individuals, age: $4.07-4.36,4.20 \pm 0.005$; stage $27-28,27.23 \pm 0.027$ ). These two groups differ significantly in age (Wilcoxon Rank Sum: $z=3.8, P=0.00007$ ). In prior work using manual egg-jiggling at stages 26-29 and measuring the VOR of every individual, the hatching response of individuals "without vestibular function" was similarly low (23\%) using criteria of $<1^{\circ}$ or $<10^{\circ}$, and it increased substantially as VOR increased to ca. 30-40 (Jung et al., 2019). Here, using the VOR of measured individuals to estimate the presence/absence of vestibular function in their unmeasured siblings allowed us to test for $\mathrm{MCH}$ in many more individuals than we could measure for VOR, but entails some classification errors. Applying our criterion to a prior dataset (Jung et al., 2019) we expect an estimated level of 14\% false positives and $22 \%$ false negatives, reducing the chance of detecting an effect of vestibular function on hatching in the current data.

For each individual, we recorded hatching response (Fig. 2B) and latency (seconds from stimulus onset) or failure to hatch after $5 \mathrm{~min}$ of post-stimulus observation (Fig. 2C). Proportion hatched was calculated per treatment per clutch.

\section{Hatching-response test: vibration playbacks}

To provide a motion-only stimulus, without concurrent tactile cues, we performed vibration playbacks to groups of embryos held in custom-made egg-trays (Warkentin et al., In press; Warkentin et al., 2019). Trays held up to 15 eggs $(\geq 8,11.79 \pm 0.25$ eggs per tray) in individual funnel-shaped spaces, allowing hatched tadpoles to slide through the tray to water below. We tested 1132 individuals in 96 trays from 63 clutches from July 25 to August 7, 2019 (age: 5.40$5.75,5.56 \pm 0.009 \mathrm{~d}$, stage: $30-33.67,31.27 \pm 0.080)$. We aimed to test embryos of the same age as the $5 \mathrm{~d}$ individuals tested with jiggling cues, but due to logistic constraints playback embryos were, on average, 4 hours older than jiggled embryos. Embryos were treated with gentamicin or as rainwater controls at age $3 \mathrm{~d}$, as described above, and moved to individual spaces in egg-trays early at embryonic age $4 \mathrm{~d}$, while eggs could be easily handled without inducing hatching. Full trays were maintained on racks over aged tap water in humidors until testing, with regular misting until age $5 \mathrm{~d}$ (Warkentin et al., In press; Warkentin et al., 2019).

We designed a synthetic low-frequency vibration stimulus to elicit high hatching rates, based on prior playbacks to $5 \mathrm{~d}$ embryos (Caldwell et al., 2009; Jung et al., 2019; Warkentin et al., In press; Warkentin et al., 2006b; Warkentin et al., 2017; Warkentin et al., 2019). We generated white noise in MATLAB and filtered it using a custom script (available upon request) to compensate for nonlinearities in the shaker transfer function and generate a frequency 
distribution similar to snake-attack vibrations (Caldwell et al., 2009), with high energy below 50 $\mathrm{Hz}$ and intensity dropping off above that (Fig. 3A). The temporal pulse pattern included a 3pulse 'primer' and a series of seven 10-pulse groups separated by $30 \mathrm{~s}$ intervals of silence (Fig. 3B). Within each pulse group, the base temporal pattern had a cycle length of $2 \mathrm{~s}$, consisting of $0.5 \mathrm{~s}$ pulses of vibration with roughly rectangular amplitude envelopes separated by $1.5 \mathrm{~s}$ intervals of silence (Fig. 3C). To record playback vibrations, we attached a small (0.14 g) AP19 accelerometer (AP Technology International B.V., Oosterhout, The Netherlands) to an egg-tray using dental wax (Warkentin et al., In press). Accelerometer output was routed through an AP5000/10 charge-to-voltage converter to a B\&K 1704 signal conditioner (Brüel \& Kjær, Nærum, Denmark), digitized with a Focusrite Scarlett $2 \mathrm{i} 2$ external sound card (focusriteplc.com), and recorded using Raven Pro 1.3 bioacoustics software (Cornell University Laboratory of Ornithology, Ithaca, NY, USA) on a Macbook Air computer. The RMS amplitude of the playback vibrations, excluding intervals of silence, was $6.5 \mathrm{~ms}^{-2}$.

Playback methods followed published work detailing vibration presentation via egg-trays (Warkentin et al., In press; Warkentin et al., 2019). For testing, we clamped egg-trays holding embryos to a custom-made interface on a rigid post attached to an electrodynamic minishaker (Model 4810; Brüel \& Kjær, Nærum, Denmark). The shaker, post, and tray were horizontally leveled, with foam supports under the post and tray edge and water under the embryos. Thus, embryos were moved horizontally and hatchlings fell into the water below. Shaker output was controlled by Audacity 2.1.0 on a 2014 Macbook Air, via a custom-made amplifier (E. Hazen, Boston University Electronic Design Facility). We recorded any hatching induced by the set-up procedure ( $\mathrm{N}=3$ individuals), then allowed five minutes for acclimation before starting the playback ( $\mathrm{N}=38$ individuals hatched during acclimation). Individuals that hatched before the stimulus started were not considered part of the test. We noted if and when (to the nearest second) each embryo hatched during stimulus playback and 3 minutes of post-playback observation (Fig. 3D-F). We then immediately (within $20 \mathrm{~min}$ ) measured VOR of a subset of individuals, including a pair of gentamicin-treated and control individuals from 32 clutches (plus 14 clutches with unpaired data). We confirmed hatching competence of embryos remaining unhatched by manually stimulating them with a blunt metal probe ( $\mathrm{N}=251$ individuals). We also used 4-di-2-ASP staining to confirm lateral line blocking in at least one individual per treated tray with hatching and to visualize neuromasts in one control per testing session ( $\mathrm{N}=43$ treated, 5 untreated individuals). We staged 3 haphazardly selected hatchlings from each tray (Warkentin, 2017).

\section{Lateral line system ontogeny}

To determine at what point during lateral line development the hatching response to jiggling cues begins, we compared the ontogeny of the lateral line system and of $\mathrm{MCH}$, using a developmental series of 79 embryos from 25 clutches from August 6-11, 2018. For each individual, we first tested for $\mathrm{MCH}$, using the same manual egg-jiggling stimulus as in the first hatching response test (Warkentin et al., 2017). Test clutches were transported just prior to hatching competence and tested in an air-conditioned laboratory of the Smithsonian Tropical Research Institute in Gamboa. We recorded latency to hatch and embryos that remained unhatched after 5 min were manually decapsulated using sharp forceps. We staged embryos under a stereoscope (Warkentin, 2017). Neuromasts were then stained using 4-di-2-ASP as described above and photographed in 
in frontal and dorsal views. The frontal view showed neuromasts in the ventral, oral, infraorbital, nasal, and supraorbital lines (Fig. 4A), while the dorsal view showed neuromasts in the nasal, supraorbital, middle, and dorsal lines (Fig. 4B). All neuromasts within each line were labeled and counted using ImageJ software (Schneider et al., 2012). We took several photos in each view, in different focal planes, framing, and magnification, then counted neuromasts in each line from the photo(s) that showed them best. Counts from supraorbital and middle neuromast lines were extrapolated from one side, assuming bilateral symmetry within individuals. When lines extended across multiple photos, we used landmarks to avoid double-counting or missing neuromasts. We averaged counts per line from two independent counters and summed them across lines to estimate the total number of neuromasts per individual (Fig. 4C, Table S1). We also measured tadpole total length from dorsal images (Fig. 4D).

\section{Statistics}

All statistical tests were carried out in the $\mathrm{R}$ statistical environment (version 3.6.2, $\mathrm{R}$ Development Core Team 2019, http:/www.r-project.org) in RStudio (version 1.2.5033, RStudio Team 2019). We used generalized linear mixed models within the 'Ime4' package (Bates et al., 2015) with clutch as a random effect and likelihood ratio tests to compare nested models for fixed effects and interaction effects on the number of neuromasts (error distribution: negative binomial), hatching responses (binomial), and first hatching latency (gamma). We used the fitconds function within the 'fitplc' package to plot curve fits for all hatching latencies (weibull) within trays (Duursma and Choat, 2017).

\section{RESULTS}

\section{Lateral line system knockout with gentamicin}

315 (gentamicin: $\chi \chi^{2}{ }_{1}=88.2, \mathrm{P}<2.2 \mathrm{e}-16$; VOR: $\chi^{2}{ }_{1}=30.4, \mathrm{P}=3.5 \mathrm{e}-8$; interaction: $\chi^{2}{ }_{1}=0.7, \mathrm{P}=0.4$, Fig.

316 2A-B). In embryos lacking vestibular function (mean age $4.17 \mathrm{~d}$ ), gentamicin reduced the

317 hatching response significantly from $10 \%$ to $1 \%\left(\chi^{2}{ }_{1}=14.4, \mathrm{P}=0.0001\right.$, Fig. $\left.2 \mathrm{~B}\right)$. Just after the

318 onset of VOR, gentamicin still reduced hatching significantly $\left(41 \%\right.$ vs. $2 \% ; \chi^{2}{ }_{1}=73.8, P<2.2 \mathrm{e}-16$, 
Fig. 2B). While both age and neuromast function increased hatching, the gentamicin effect on $\mathrm{MCH}$ decreased with age (age: $\chi^{2}{ }_{3}=200.1, \mathrm{P}<2.2 \mathrm{e}-16$; gentamicin: $\chi^{2}{ }_{1}=105.7, \mathrm{P}<2.2 \mathrm{e}-16$; interaction: $\chi^{2}{ }_{3}=19.9, \mathrm{P}=0.0002$; Fig. $\left.2 \mathrm{~B}\right)$. At $4.7 \mathrm{~d}$, gentamicin still significantly reduced hatching $\left(70 \%\right.$ vs. $\left.41 \% ; \chi^{2}{ }_{1}=35.4, \mathrm{P}=2.7 \mathrm{e}-09\right)$ but at $5.4 \mathrm{~d}$, close to spontaneous hatching, all jiggled eggs hatched, with or without functional neuromasts (Fig. 2B).

Latency to hatch decreased with age and lateral line function (age: $\chi^{2}{ }_{3}=79.2, P<2.2 \mathrm{e}-16$; gentamicin: $\chi^{2}{ }_{1}=36.9, \mathrm{P}=1.266 \mathrm{e}-09$; interaction: $\chi^{2}{ }_{3}=3.8, \mathrm{P}=0.29$; Fig. $2 \mathrm{C}$ ). The low hatching response of gentamicin-treated embryos before and just after the onset of VOR limited our sample of latency, reducing statistical power for comparisons (Fig. 2C). However, gentamicin treatment increased latency to hatch at both $4.7 \mathrm{~d}\left(\chi^{2}{ }_{1}=17.1, \mathrm{P}=3.5 \mathrm{e}-05\right)$ and $5.4 \mathrm{~d}\left(\chi^{2}{ }_{1}=21.2\right.$, $\mathrm{P}=4.1 \mathrm{e}-06$ ) with no indication that the effect decreased with age (interaction: $\chi^{2}{ }_{1}=2.84, \mathrm{P}=0.09$;

331 Fig. 2C).

Hatching-response test: vibration playbacks

To assess if egg motion alone can stimulate the lateral line system, we used vibration playbacks

336 to shake gentamicin-treated and untreated embryos held in custom-made egg trays. In these 337 playbacks, lateral line function had no effect on the hatching response of embryos $\left(\chi^{2}{ }_{1}=1.8\right.$, $\mathrm{P}=0.1787$, Fig. 2D) or timing of hatching $\left(\chi^{2}{ }_{1}=1.1, \mathrm{P}=0.2986\right.$, Fig. 2E-F $)$.

\section{Lateral line system ontogeny}

342 The number of neuromasts in all seven lines increased with developmental stage (Fig. 4C, Table

343 S1). Total number of neuromasts increased with size (Fig. 4D), age (Fig. 4E) and, most strongly, 344 developmental stage (Fig. 4F). From stage 27 to 29, the number of neuromasts more than 345 doubled (Fig. 4F). Both developmental stage $\left(\chi^{2}{ }_{1}=50.9, \mathrm{P}=9.5 \mathrm{e}-13\right)$ and the total number of 346 neuromasts $\left(\chi^{2}=15.7, \mathrm{P}=7.5 \mathrm{e}-5\right)$ were significant predictors of hatching in egg-jiggling 347 experiments (Fig. 4G). When embryos had fewer than a threshold number of neuromasts (247), 348 none hatched, whereas embryos with more neuromasts often hatched. 


\section{DISCUSSION}

352 We demonstrate that the developing lateral line and vestibular systems both contribute to escape-

353 hatching of red-eyed treefrog embryos, and that the roles of these sensors change during

354 development and vary with disturbance cue type.

\section{Lateral line system knockout with gentamicin}

Using gentamicin, we achieve complete lateral line ablation in A. callidryas embryos with no evidence of vestibular system damage (Fig. 1). Others found evidence that gentamicin can cause vestibular system damage when administered intramuscularly (Bagger-Sjoback, 1997; Yan et al., 1991) or by direct immersion post-hatching (Simmons et al., 2004; Song et al., 1995; Van Trump

362 et al., 2010). Our study is the first to investigate the effects of gentamicin administered

363 incrementally to embryos developing in ovo, which was necessary to avoid water loss from eggs

364 and, later, test for hatching responses. The gradual passage of gentamicin across the vitelline

365 membrane into the perivitelline space while eggs were in the treatment bath, and the potential

366 loss of gentamicin from older eggs maintained in egg-trays before vibration playbacks, means we

367 do not know the precise concentrations embryos were exposed to over time. However, our

368 longest exposure durations and peak exposure concentrations exceeded those in previous studies

369 (Simmons et al., 2004; Song et al., 1995; Van Trump et al., 2010), supporting that for some

370 animals under some exposure conditions gentamicin can selectively damage hair cells in the

371 lateral line without impairing the function of hair cells in the vestibular system. Lateral line

372 neuromasts are directly exposed to the fluid bathing an embryo, but hair cells of the inner ear are

373 not, and the barriers protecting these internal cells likely change with development.

375 Notably, we found no evidence for ear damage in early stages, at the onset of vestibular function, 376 and also in more developed 5 day old embryos. Immature and recently regenerated hair cells are 377 resistant to aminoglycoside antibiotics (Dai et al., 2006; Hashino and Salvi, 1996; Murakami et 378 al., 2003; Van Trump et al., 2010). Thus, in the youngest tested embryos, vestibular hair cells 379 may have had only brief gentamicin exposure after maturing to a point of vulnerability. In the 380 lateral line system, neuromasts began to regain fluorescence, when stained with DiAsp, within 
381 hours of hatching and cessation of gentamicin exposure. We suspect this was due to maturation

382 of gentamicin-resistant developing hair cells. Embryos tested at 5 days would have had

383 functional hair cells in their ears for over $24 \mathrm{~h}(29.8 \mathrm{~h}$ from mean onset of VOR to mean testing

384 age) under gentamicin treatment, yet we also found no evidence for vestibular damage in these

385 older embryos. This suggests that, compared to more mature tadpoles (Bagger-Sjoback, 1997;

386 Simmons et al., 2004; Van Trump et al., 2010; Yan et al., 1991), embryonic anatomy may better

387 protect otic hair cells against externally administered gentamicin.

Hatching-response test: manual egg jiggling

In embryos lacking vestibular function, a significant effect of gentamicin treatment on hatching response reveals that the onset of lateral line function precedes the onset of vestibular function

393 and plays a key role in very early MCH (Fig. 2B). Immediately following the onset of VOR, the

394 lateral line system continues to contribute strongly to risk assessment and hatching. The higher

395 hatching rate in VOR-positive animals (Fig. 2B) is consistent with a key role of otoconial organs

396 in embryonic vibration sensing (Jung et al., 2019). However, at the onset of MCH neither lateral

397 line nor vestibular function alone enabled a strong response; the multimodal combination of

398 input from both senses greatly increased the likelihood of hatching in a simulated attack (Fig.

399 2B).

401 Soon after $A$. callidryas gain hatching competence, the lateral line system plays a critical role in 402 sensing and responding to predator cues. We tested the effect of gentamicin on jiggling-induced 403 hatching in two later periods to determine if the dependence of $\mathrm{MCH}$ on lateral line function 404 changes developmentally. In A. callidryas, embryos hatch spontaneously from 5-7 d, while 405 younger embryos almost never hatch if undisturbed (Güell and Warkentin, 2018; Hite et al., 406 2018; Warkentin, 2000; Warkentin et al., 2001). From age 4 to 5 d, embryos become more likely 407 to escape during snake and wasp attacks (Gomez-Mestre and Warkentin, 2007; Warkentin, 1995; 408 Warkentin, 2000) and to hatch in vibration playbacks (Jung et al., 2019; Warkentin et al., In 409 press; Warkentin et al., 2019). Over this same developmental period, our results show that MCH 410 responses become less dependent on multimodal input from the lateral line plus vestibular 
411 system. This might reflect increasing strength of vestibular input as embryo ears develop (Jung et 412 al., 2018).

414 When animals use multimodal sensory integration to inform behavior, a sensor may contribute to 415 a response without being required for its occurrence (Angelaki and Cullen, 2008). We examined 416 latency from stimulus onset to hatching response (Fig. 2C) as a potentially more sensitive 417 indicator of lateral line system contributions to embryo decisions, since latency affects escape 418 success during predator attacks (Almanzar and Warkentin, 2018; Chaiyasarikul and Warkentin, 419 2017). We found that even embryos near the stage of spontaneous hatching, when they have a 420 very strong vestibular-mediated hatching response, still use lateral line input to accelerate their 421 response to simulated attack cues (Fig. 2C).

425 The fact that lateral line function had no effect on the proportion of embryos hatching (Fig. 3D) 426 or their latency to hatch (Fig. 3E) in response to motion-only vibration playbacks suggests that 427 only a subset of more complex physical disturbances stimulate the lateral line system, while 428 potentially any egg motion may stimulate the vestibular system. Thus, some embryos in attacked 429 egg clutches receive unimodal vestibular stimulation while others receive multimodal vestibular 430 and lateral line system input. Some may also receive input from cutaneous touch receptors 431 (Blaxter, 1987; O’Brien et al., 2012). Given the role of lateral line system input in reducing 432 hatching latency, as well as increasing hatching likelihood in younger embryos, this variation in 433 the type(s) of sensory input an embryo receives under different predation contexts likely 434 contributes to the variation in the likelihood and timing of hatching during attacks (Almanzar and 435 Warkentin, 2018; Warkentin, 2000; Warkentin et al., 2006a). The variation in received 436 mechanosensory stimuli within a clutch may also be a mechanism contributing to threat-sensitive 437 embryo behavior (Ferrari and Chivers, 2009; Hughey et al., 2015; Mathis et al., 2008; Van 438 Buskirk, 2016); since predators must touch eggs to eat them, the risk of mortality during attacks 439 is likely higher for eggs receiving multimodal cues than for those receiving motion cues alone.

\section{$441 \quad$ Lateral line system ontogeny}


443 In a recent study, we found hatching in response to egg-jiggling to begin, on average, at stage

44427.3 and considered hatching "consistent" at stage 28.8 (Fig. 4C), the second time both of two

445 tested siblings hatched (Jung et al., 2019; Warkentin et al., 2017). This known onset of MCH

446 aligns ontogenetically with a rapid increase of neuromast number in developing embryos (Fig.

447 4C). The pattern of a neuromast-number threshold for hatching (Fig. 4G) suggests that lateral

448 line system development may limit the onset of disturbance cue sensing and associated hatching

449 behavior.

\section{Lateral line morphology in comparative context}

453 The number of neuromasts at hatching and their proliferation after hatching varies greatly across

454 taxa. Some fishes hatch with only two functional neuromasts, and early larvae simply float in the 455 water column [e.g. flounder (Kawamura and Ishida, 1985), tuna (Kawamura et al., 2003), 456 grouper (Mukai et al., 2006), catfish (Mukai et al., 2010)]. Subsequent rapid lateral line system

457 development is correlated with behavioral changes (avoiding obstacles, feeding, migrating, 458 settling, and surviving seasonal floods) and parallels rapid development of other sense organs 459 such as eyes, ears, taste buds, olfactory epithelium (Kawamura and Ishida, 1985; Kawamura et 460 al., 2003; Mukai et al., 2006; Mukai et al., 2010). Neuromast proliferation can also occur slowly. 461 For instance, cod larvae hatch with five lateral body neuromasts, and only add one more by 462 feeding onset, 2-3 weeks later (Blaxter, 1984). The developmental stage at which neuromast 463 function begins differs among species, and appears related to hatchlings' habitat and habits 464 (Otsuka and Nagai, 1997). For instance, ayu hatch with 20 pairs of well-developed neuromasts 465 and migrate downstream immediately upon hatching (Kawamura et al., 1983). In contrast, pale 466 chub hatch without a single neuromast and remain in the spawning bed for $4 \mathrm{~d}$, during which 467 neuromasts develop rapidly; at emergence into the river, larvae are responsive to water flow and 468 have nearly caught up to ayu in neuromast number (Kawamura et al., 1983). Across species, 469 developmental increases in the number of neuromasts are closely linked to the ontogeny of 470 mechanosensory-guided behavior (Blaxter and Fuiman, 1989; Kawamura and Ishida, 1985; 471 Llanos-Rivera et al., 2014). However, neuromast size, shape, and hair cell polarity can also affect 472 mechanosensory sensory function (Becker et al., 2016; Webb and Shirey, 2003). 
474 Anatomically and physiologically, amphibian neuromasts resemble superficial neuromasts of

475 teleost fishes (Metcalfe, 1985; Simmons et al., 2004). However, we know relatively little about

476 their early development, except in a few species. At hatching, the salamander Ambystoma

477 mexicanum has all 60 neuromasts, while in the frog Lithobates (Rana) pipiens most neuromasts

478 have not yet formed; however, by the onset of feeding, the lateral line appears fully formed and

479 functional in both species (Smith et al., 1988). Among amphibians, early lateral line system

480 development has been characterized in detail in Xenopus laevis (Roberts et al., 2009; Shelton,

481 1970; Simmons et al., 2004; Winklbauer, 1989), but studies rarely distinguish hatching timing.

482 Reported hatching stage varies such that X. laevis have between 0 (Carroll and Hedrick, 1974)

483 and 14 neuromasts at hatching, but embryos with just 6-8 neuromasts swim into water currents

484 and responsiveness increases over the next $10 \mathrm{~h}$ with an increase in neuromast number (Roberts

485 et al., 2009). In our study system, the hatching response of $A$. callidryas embryos to disturbance

486 begins only when they have hundreds of neuromasts (Fig. 4G). Despite the large increase in

487 neuromast number, there appears to be little change in neuromast size (personal observation from

488 confocal images by María José Salazar Nicholls and Julie Jung) or shape (Cohen et al., 2019)

489 from 3 to 5 days post oviposition. It is not yet clear how physical disturbance of eggs stimulates

490 the neuromasts of embryos inside them; however, induced perturbations of perivitelline fluid

491 motion within the egg capsule may provide a weaker or less clear stimulus to the lateral line

492 system than currents in open water do after hatching. Additionally, the cost of unnecessarily

493 swimming into a current may be lower than that of hatching prematurely.

495 The number of neuromasts A. callidryas have at hatching is high, even compared to other

496 anurans in late larval development (Lannoo, 1987). A. callidryas that hatched in response to egg-

497 jiggling, at 7.7-11.0 mm total length, had neuromast counts of 323.6 \pm 11.9 (range 247-434).

498 For comparison, in a study of 36 other anuran species examined in late larval development, at

499 their expected peak of neuromast numbers (Lannoo, 1987; Winklbauer, 1989), the most

500 neuromasts reported was 332 in Rana aurora, at 25-27.5 mm snout-vent length (Lannoo, 1987).

501 Since lateral line development depends on the size of the animal, and tadpoles tend to add

502 neuromasts during post-hatching development (Fabrezi et al., 2012; Winklbauer, 1989), these

503 other species presumably have fewer neuromasts at hatching. This suggests that $A$. callidryas 
504 have precocious lateral line development, as well as high neuromast numbers. However, we

505 know nothing about lateral line ontogeny in other anurans with documented or suspected mechanosensory-cued escape-hatching behavior (Brown and Iskandar, 2000; Brown et al., 2010;

507 Buckley et al., 2005; Chivers et al., 2001; Gomez-Mestre et al., 2008; Poo and Bickford, 2014;

508 Sih and Moore, 1993; Smith and Fortune, 2009; Touchon et al., 2011). Egg predation might be a

509 selective force favoring earlier or greater development of mechanosensory systems. A

510 comparative analysis of lateral line and vestibular system development in relation to the

511 distribution of MCH in anurans (Warkentin, 2011b; Warkentin, 2011a) would be informative.

512 Assessing links between sensory morphology and embryo behavior could reveal patterns of

513 functional variation and adaptive evolution and provide further insight into how embryos use

514 sensory information.

516 Embryos across diverse taxa respond to physical disturbance cues from many ecologically 517 relevant sources (Warkentin, 2011b; Warkentin, 2011a; Warkentin et al., In press). In contexts 518 such as antipredator defense (Doody and Paull, 2013; Warkentin, 2005) and sibling hatching 519 synchronization (Endo et al., 2019; Noguera and Velando, 2019), embryos' ability to sense these 520 cues is often essential for their survival, yet we know very little about the sensory systems that 521 mediate $\mathrm{MCH}$ or even, in many cases, which elements of physical disturbance cues are most 522 relevant. Herein, we show that to detect egg-disturbance cues A. callidryas embryos use their 523 vestibular system, a sensory mechanism likely to be relevant across vertebrates, and their lateral 524 line system, a mechanism which may contribute to $\mathrm{MCH}$ in other frogs and fishes. Our study 525 serves as proof-of-concept for the feasibility of combining neuromast ablation in ovo with 526 hatching-response tests, and it highlights the value of latency as a sensitive response variable in 527 the context of multimodal mechanosensing. The methods we present open opportunities for 528 comparative research into embryo sensory ecology with other species that hatch in response to 529 mechanosensory cues. Our findings provide insight into the functional roles of two different 530 mechanosensory systems prior to hatching and reveal new possibilities for exploring embryonic 531 sensory perception across taxa. 


\section{Acknowledgments}

This research was funded by the National Science Foundation (IOS-1354072 to KMW and James Gregory McDaniel), and conducted under permits SC/A-10-18 and SE/A-42-19 from the Panamanian Ministerio de Ambiente and STRI IACUC protocol 2017-0601-2020-2. We thank J. Gregory McDaniel for collaboration in biotremology, including development of the tadpole rotator and egg-tray playback system, Jacqueline Webb and Andrea Simmons for advice on neuromast blocking, Estefany Caroline Guevara Molina, Luis Alberto Rueda Solano, and Henry Macías for help with egg jiggling and care, Casey Lam for assistance measuring eye angles and body angles from photographs, members of the Gamboa Frog Group at STRI and BU Egg Science Research Group for discussions of this research, and Jacqueline Webb and Pete Buston for helpful comments on the manuscript.

\section{Competing Interests}

No competing interests declared.

\section{Author Contributions}

Conceptualization: J.J. and K.M.W.

Methodology: J.J., S.J.S.R., and K.M.W.

Software: J.J.

Validation: J.J., S.J.S.R., and K.M.W.

Formal analysis: J.J.

Investigation: J.J. and S.J.S.R.

Resources: K.M.W.

Data curation: J.J.

Writing - original draft: J.J.

Writing - review and editing: J.J., S.J.S.R., and K.M.W.

Visualization: J.J.

Supervision: K.M.W.

Project administration: K.M.W.

Funding acquisition: K.M.W. 


\section{Figures}

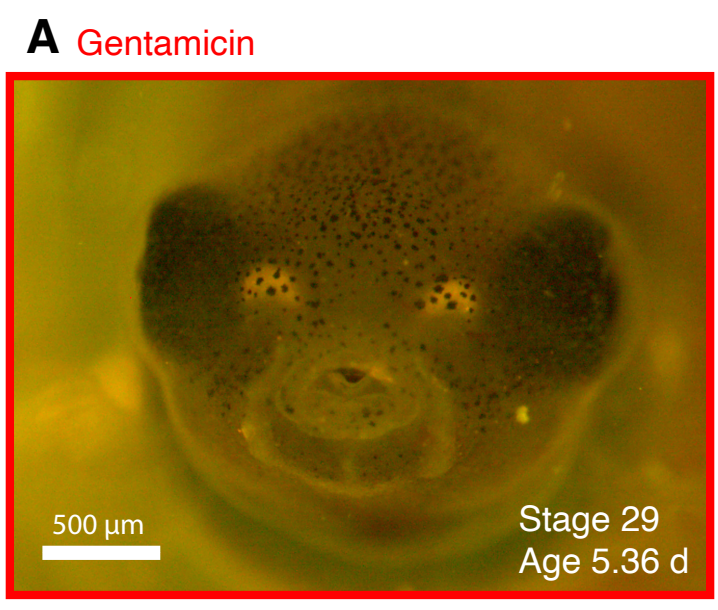

\section{B Control}
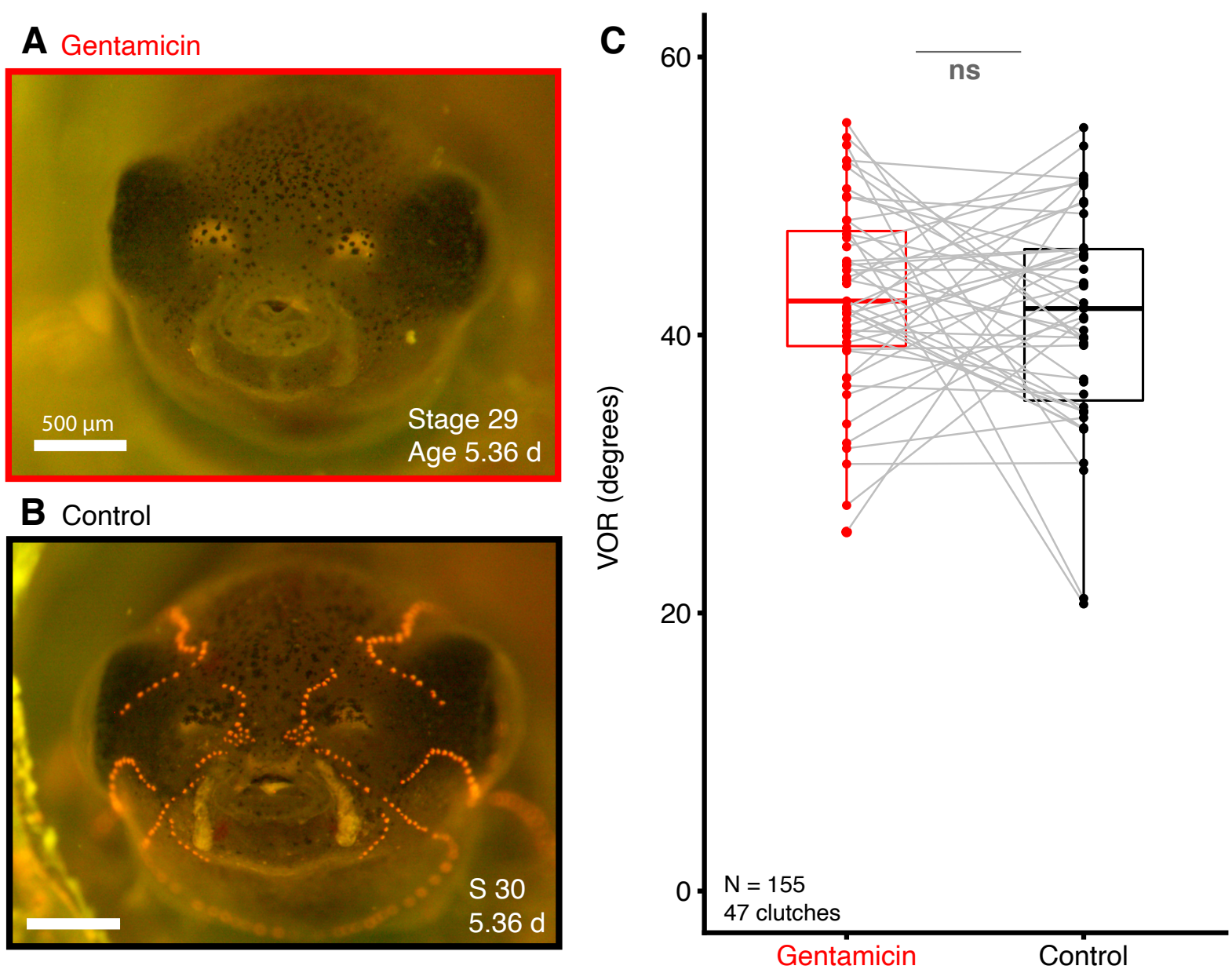

Figure 1. Gentamicin ablates lateral line system function with no effect on vestibular system. (A) Representative gentamicin-treated individual, showing complete ablation of functional neuromasts, and (B) age- and stage-matched control sibling, showing functional neuromasts (orange). (C) VOR amplitude of gentamicin-treated and control A. callidryas. Gray lines connect points representing stage-matched siblings, in the same or adjacent developmental stages, across treatments. ns $\mathrm{P}>0.05$. 
A

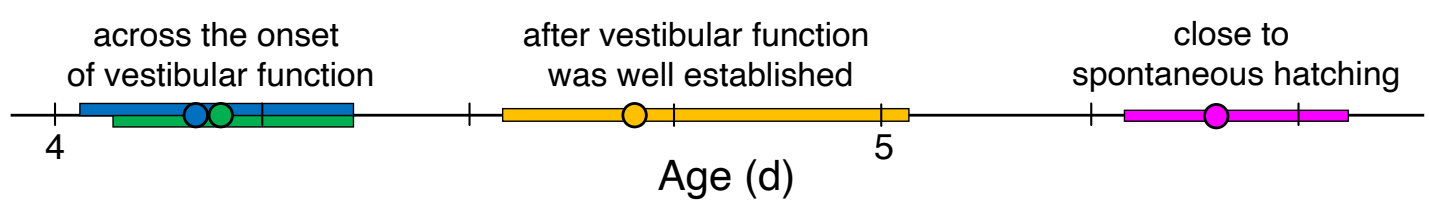

B
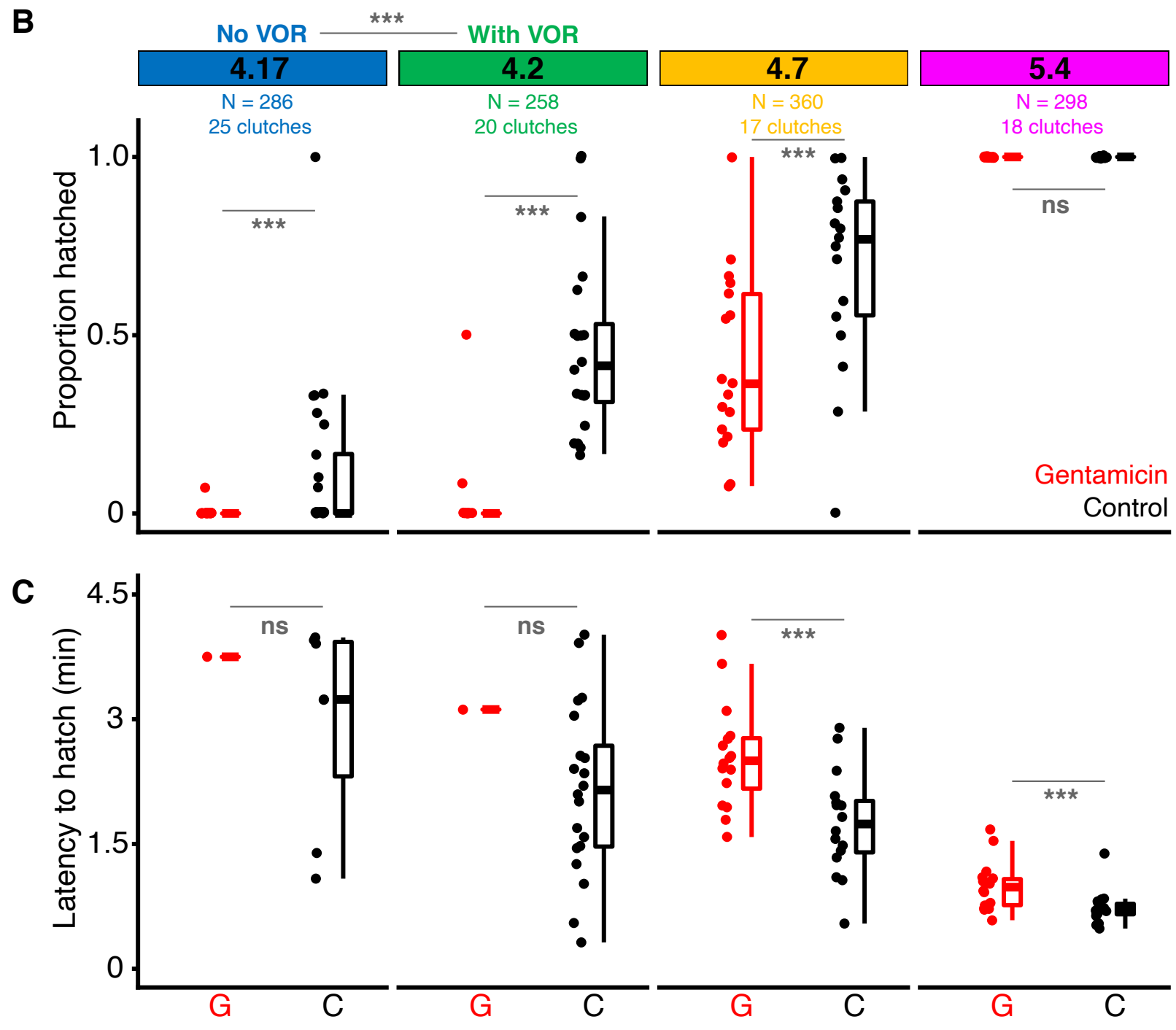

Treatment

Figure 2. Ontogeny of the hatching response to egg-jiggling by gentamicin-treated and control $A$. callidryas embryos, across and after the onset of vestibular function (indicated by VOR). (A) Developmental timeline of testing periods, with mean ages (points) and ranges (rectangles) color coded, (B) hatching responses, and (C) latencies. Data points are clutch-means and boxplots show means, quantiles, and $1.5 * \mathrm{IQR}$ across clutches, within treatment $\times$ age category; ns $\mathrm{P}>0.05, * * * \mathrm{P}<0.001$. 
A
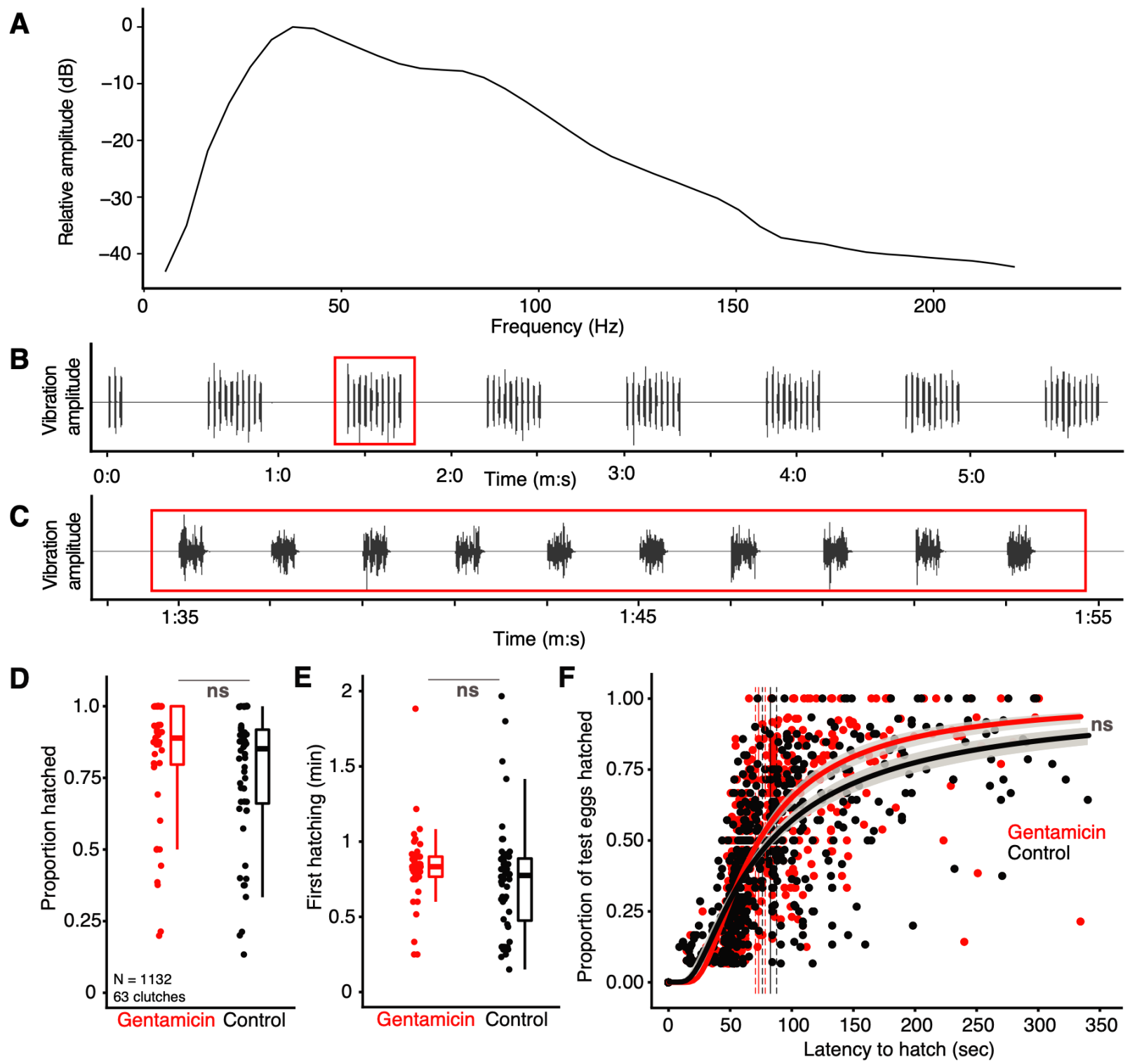

Figure 3. Hatching responses of gentamicin-treated and control $\boldsymbol{A}$. callidryas embryos (mean age $5.56 \mathrm{~d}$, stage 31.3 ) to motion-only vibration playback. (A) Frequency spectrum from recording of playback stimulus, (B) waveform of entire stimulus, with (C) waveform of a single pulse group in red box, showing the base temporal pattern $(0.5 \mathrm{~s}$ duration, $1.5 \mathrm{~s}$ interval). (D) Proportion of embryos hatched and (E) latency for the first individual to hatch, after stimulus began. Points are values per tray, boxplots show means, quantiles, and $1.5^{*} \mathrm{IQR}$ across trays. (F) All individual hatching latencies (points) in playbacks, with Weibull curve fits and 95\% CI (shading). Vertical solid lines indicate the mean latency by which $50 \%$ of individuals within treatments had hatched (estimated from bootstrap), dashed lines indicate the $95 \% \mathrm{CI}$. ns P > 0.01 . 


Figure 4. Lateral line system ontogeny and development of the hatching response of $A$. callidryas embryos to egg-jiggling. Representative (A) frontal and (B) dorsal views of hatchlings stained with 4-di-2-ASP to show neuromasts, with lines color-labeled. (C) Mean number of neuromasts in each line (bilaterally) across development, \pm SEM. Inset shows previously reported (Jung et al., 2019; Warkentin et al., 2017) stages when MCH is first and consistently expressed; diamonds represent means and 95\% confidence intervals, box and whiskers show interquartile range (IQR) and extent of data to $\pm 1.5 \times \mathrm{IQR}$. Total number of neuromasts increased with (D) total length $\left(\chi^{2}=5.2, \mathrm{df}=1, \mathrm{P}=0.02319\right),(\mathrm{E})$ age $\left(\chi^{2}=62.4, \mathrm{df}=1\right.$, $\mathrm{P}<2.9 \mathrm{e}-15)$, and $(\mathrm{F})$ developmental stage $\left(\chi^{2}=6263.8, \mathrm{df}=1, \mathrm{P}<2.2 \mathrm{e}-16\right.$; linear regression and $95 \%$ $\mathrm{CI}$ indicated). (G) Hatching response increased with neuromast number; predicted curve fit (dashed line) and 95\% CI (shading) from binomial generalized linear mixed model are indicated. For $(\mathrm{G}, \mathrm{H})$ categorical variables are jittered to show data points and stages are color-coded. Dotted lines $(\mathrm{D}, \mathrm{E}, \mathrm{G})$ show the threshold number of neuromasts at which hatching began. 
Table S1. Lateral line system ontogeny. Mean $( \pm \mathrm{SE})$ number of neuromasts in each line (bilaterally) of the lateral line system in A. callidryas embryos across the onset of mechanosensory-cued hatching.

\begin{tabular}{lc|ccccccc|c}
\hline \hline Stage & $n$ & Infraorbital & Supraorbital & Naris & Oral & Ventral & Middle* & Dorsal & Bilateral Total \\
\hline 25 & 20 & 0.05 & 10.90 & 0.33 & 0.00 & 0.03 & 9.20 & 1.62 & $22.12 \pm 5.7$ \\
26 & 13 & 2.08 & 33.81 & 2.85 & 0.65 & 0.12 & 63.69 & 7.65 & $110.85 \pm 15.9$ \\
27 & 2 & 5.25 & 26.00 & 5.75 & 7.50 & 2.50 & 97.50 & 10.50 & $155.00 \pm 42.5$ \\
28 & 17 & 14.24 & 52.24 & 14.76 & 12.74 & 6.71 & 125.24 & 12.76 & $238.68 \pm 20.4$ \\
29 & 25 & 22.36 & 64.96 & 23.52 & 26.24 & 10.30 & 153.64 & 16.24 & $317.26 \pm 11.8$ \\
31 & 1 & 21.00 & 91.00 & 29.00 & 45.00 & 26.50 & 141.00 & 17.00 & 370.50 \\
32 & 1 & 28.00 & 89.00 & 35.00 & 56.50 & 34.50 & 179.00 & 12.00 & 434.00 \\
\hline \hline
\end{tabular}

* one side counted, values presented assume symmetry 


\section{References}

Almanzar, A. and Warkentin, K. M. (2018). How development changes escape-hatching success in snake attacks: a video analysis of red-eyed treefrog embryo behavior and performance. Integr. Comp. Biol. 58, E267.

Angelaki, D. E. and Cullen, K. E. (2008). Vestibular system: the many facets of a multimodal sense. Annu. Rev. Neurosci. 31, 125-150.

Bacher, S., Casas, J., Wäckers, F. and Dorn, S. (1997). Substrate vibrations elicit defensive behaviour in leafminer pupae. J. Insect Physiol. 43, 945-952.

Bagger-Sjoback, D. (1997). Effect of streptomycin and gentamicin on the inner ear. Ann. N. Y. Acad. Sci. 830, 120-129.

Bates, D., Mächler, M., Bolker, B. and Walker, S. (2015). Fitting linear mixed-effects models using lme4. J. Stat. Softw. 67, 1-48.

Becker, E. A., Bird, N. C. and Webb, J. F. (2016). Post-embryonic development of canal and superficial neuromasts and the generation of two cranial lateral line phenotypes. $J$. Morphol. 277, 1273-1291.

Blaxter, J. H. S. (1984). Neuromasts and cupular growth of cod larvae. Flodevigen Rapp. 1, $183-188$.

Blaxter, J. H. S. (1987). Structure and development of the lateral line. Biol. Rev. 62, 471-514.

Blaxter, J. H. S. and Fuiman, L. A. (1989). Function of the free neuromasts of marine teleost larvae. In The Mechanosensory Lateral Line (ed. Coombs, S., Görner, P., and Münz, H.), pp. 481-499. New York, NY: Springer.

Bleckmann, H. (1980). Reaction time and stimulus frequency in prey localization in the surfacefeeding fishAplocheilus lineatus. J. Comp. Physiol. 140, 163-172.

Braun, C. B. and Coombs, S. (2000). The overlapping roles of the inner ear and lateral line: the active space of dipole source detection. Philos. Trans. R. Soc. Lond. B. Biol. Sci. 355, 1115-1119.

Brown, R. M. and Iskandar, D. T. (2000). Nest site selection, larval hatching, and advertisement calls, of Rana arathooni from Southwestern Sulawesi (Celebes) Island, Indonesia. J. Herpetol. 34, 404-413.

Brown, J. L., Morales, V. and Summers, K. (2010). A key ecological trait drove the evolution of biparental care and monogamy in an amphibian. Am. Nat. 175, 436-446.

Brownell, P. H. and Leo van Hemmen, J. (2001). Vibration sensitivity and a computational theory for prey-localizing behavior in sand scorpions. Integr. Comp. Biol. 41, 1229-1240. 
Buckley, C. R., Michael, S. F. and Irschick, D. J. (2005). Early hatching decreases jumping performance in a direct-developing frog, Eleutherodactylus coqui. Funct. Ecol. 19, 6772.

Caldwell, M. S., McDaniel, J. G. and Warkentin, K. M. (2009). Frequency information in the vibration-cued escape hatching of red-eyed treefrogs. J. Exp. Biol. 212, 566-575.

Carroll, E. J. and Hedrick, J. L. (1974). Hatching in the toad Xenopus laevis: Morphological events and evidence for a hatching enzyme. Dev. Biol. 38, 1-13.

Castellanos, I. and Barbosa, P. (2006). Evaluation of predation risk by a caterpillar using substrate-borne vibrations. Anim. Behav. 72, 461-469.

Chaiyasarikul, A. and Warkentin, K. M. (2017). Escape hatching of red-eyed treefrogs in wasp attacks: how development changes survival. Integr. Comp. Biol. 57, e26.

Chivers, D. P., Kiesecker, J. M., Marco, A., Devito, J., Anderson, M. T. and Blaustein, A. R. (2001). Predator-induced life history changes in amphibians: egg predation induces hatching. Oikos 92, 135-142.

Cocroft, R. B., Gogala, M., Hill, P. S. M. and Wessel, A. eds. (2014). Studying Vibrational Communication. Berlin Heidelberg: Springer-Verlag.

Cohen, K. L., Piacentino, M. L. and Warkentin, K. M. (2019). Two types of hatching gland cells facilitate escape hatching at different developmental stages in red-eyed treefrogs, Agalychnis callidryas (Anura: Phyllomedusidae). Biol. J. Linn. Soc. 126, 751-767.

Dai, C. F., Mangiardi, D., Cotanche, D. A. and Steyger, P. S. (2006). Uptake of fluorescent gentamicin by vertebrate sensory cells in vivo. Hear. Res. 213, 64-78.

Doody, J. S. and Paull, P. (2013). Hitting the ground running: environmentally cued hatching in a lizard. Copeia 2013, 160-165.

Doody, J. S., Stewart, B., Camacho, C. and Christian, K. (2012). Good vibrations? Sibling embryos expedite hatching in a turtle. Anim. Behav. 83, 645-651.

Duursma, R. and Choat, B. (2017). fitplc - an R package to fit hydraulic vulnerability curves. $J$. Plant Hydraul. 4, e002-e002.

Elepfandt, A. (1982). Accuracy of taxis response to water waves in the clawed toad (Xenopus laevis Daudin) with intact or with lesioned lateral line system. J. Comp. Physiol. 148, $535-545$.

Endo, J., Takanashi, T., Mukai, H. and Numata, H. (2019). Egg-cracking vibration as a cue for stink bug siblings to synchronize hatching. Curr. Biol. 29, 143-148.

Fabrezi, M., Quinzio, S., Goldberg, J. and Sá, R. (2012). The development of Dermatonotus muelleri (Anura: Microhylidae: Gastrophryninae). J. Herpetol. 46, 363-380. 
Ferrari, M. C. O. and Chivers, D. P. (2009). Sophisticated early life lessons: threat-sensitive generalization of predator recognition by embryonic amphibians. Behav. Ecol. 20, 12951298.

Gomez-Mestre, I. and Warkentin, K. M. (2007). To hatch and hatch not: similar selective trade-offs but different responses to egg predators in two closely related, syntopic treefrogs. Oecologia 153, 197-206.

Gomez-Mestre, I., Wiens, J. J. and Warkentin, K. M. (2008). Evolution of adaptive plasticity: risk-sensitive hatching in neotropical leaf-breeding treefrogs. Ecol. Monogr. 78, 205-224.

Güell, B. A. and Warkentin, K. M. (2018). When and where to hatch? Red-eyed treefrog embryos use light cues in two contexts. PeerJ 6, e6018.

Harris, G. G., Frishkopf, L. S. and Flock, Å. (1970). Receptor potentials from hair cells of the lateral line. Science 167, 76-79.

Hashino, E. and Salvi, R. J. (1996). Regenerated hair cells exhibit a transient resistance to aminoglycoside toxicity. Brain Res. 720, 172-182.

Hernández, P. P., Olivari, F. A., Sarrazin, A. F., Sandoval, P. C. and Allende, M. L. (2007). Regeneration in zebrafish lateral line neuromasts: expression of the neural progenitor cell marker sox 2 and proliferation-dependent and-independent mechanisms of hair cell renewal. Dev. Neurobiol. 67, 637-654.

Hill, P., Lakes-Harlan, R., Mazzoni, V., Narins, P. M., Virant-Doberlet, M. and Wessel, A. eds. (2019). Biotremology: Studying Vibrational Behavior. Springer International Publishing.

Hill, P. S. M. (2009). How do animals use substrate-borne vibrations as an information source? Naturwissenschaften 96, 1355-1371.

Hite, J. L., Hughey, M. C., Warkentin, K. M. and Vonesh, J. R. (2018). Cross-ecosystem effects of terrestrial predators link treefrogs, zooplankton, and aquatic primary production. Ecosphere 9, e02377.

Hoekstra, D. and Janssen, J. (1985). Non-visual feeding behavior of the mottled sculpin, Cottus bairdi, in Lake Michigan. Environ. Biol. Fishes 12, 111-117.

Horn, E. and Sebastian, C. (1996). A hypergravity related sensitive period during the development of the roll induced vestibuloocular reflex in an amphibian (Xenopus laevis). Neurosci. Lett. 216, 25-8.

Horn, E., Mack, R. and Lang, H. G. (1986). The development of the static vestibulo-ocular reflex in the southern clawed toad, Xenopus laevis. II. Animals with acute vestibular lesions. J. Comp. Physiol. [A] 159, 879-85. 
Hughey, M. C., Rogge, J. R., Thomas, K., McCoy, M. W. and Warkentin, K. M. (2015). Escape-hatching responses of individual treefrog embryos vary with threat level in wasp attacks: a mechanistic analysis. Behaviour 152, 1543-1568.

Jung, J., Güell, B. A. and Warkentin, K. M. (2018). Inner ear development across onset and improvement of escape-hatching ability in red-eyed treefrogs: a confocal and $\mu \mathrm{CT}$ analysis. Integr. Comp. Biol. 58, e348.

Jung, J., Kim, S. J., Pérez Arias, S. M., McDaniel, J. G. and Warkentin, K. M. (2019). How do red-eyed treefrog embryos sense motion in predator attacks? Assessing the role of vestibular mechanoreception. J. Exp. Biol. 222, jeb206052.

Karlsen, H. E. and Sand, O. (1987). Selective and Reversible Blocking of the Lateral Line in Freshwater Fish. J. Exp. Biol. 133, 249-262.

Kawamura, G. and Ishida, K. (1985). Changes in sense organ morphology and behaviour with growth in the flounder Paralichthys olivaceus. Nippon Suisan Gakkaishi 51, 155-165.

Kawamura, G., Mukai, Y. and Ohta, H. (1983). Morphology of the eye and free neuromast of larval ayu and pale chub and its relation to behaviour in water flow. Nippon Suisan Gakkaishi 49, 1527-1532.

Kawamura, G., Masuma, S., Tezuka, N., Koiso, M., Jinbo, T. and Namba, K. (2003). Morphogenesis of sense organs in the bluefin tuna Thunnus orientalis. Proc. 26th Annu. Larval Fish Conf. 123-135.

Kroese, A. B. A. and van den Bercken, J. (1982). Effects of ototoxic antibiotics on sensory hair cell functioning. Hear. Res. 6, 183-197.

Lannoo, M. J. (1987). Neuromast topology in anuran amphibians. J. Morphol. 191, 115-129.

Lannoo, M. J. (1999). Integration: nervous and sensory systems. In Tadpoles: The Biology of Anuran Larvae (ed. McDiarmid, R. and Altig, R.), pp. 149-169. Chicago, IL: University of Chicago Press.

Llanos-Rivera, A., Herrera, G., Tarifeño, E. and Castro, L. R. (2014). Development of free neuromasts in Engraulis ringens and Strangomera bentincki (Teleostei, Clupeiformes) early larvae. Lat. Am. J. Aquat. Res. 42, 264-270.

Ma, E. Y., Rubel, E. W. and Raible, D. W. (2008). Notch signaling regulates the extent of hair cell regeneration in the zebrafish lateral line. J. Neurosci. 28, 2261-2273.

Mathis, A., Ferrari, M. C. O., Windel, N., Messier, F. and Chivers, D. P. (2008). Learning by embryos and the ghost of predation future. Proc. R. Soc. B Biol. Sci. 275, 2603-2607.

Metcalfe, W. K. (1985). Sensory neuron growth cones comigrate with posterior lateral line primordial cells in zebrafish. J. Comp. Neurol. 238, 218-224. 
Mogdans, J. (2019). Sensory ecology of the fish lateral-line system: Morphological and physiological adaptations for the perception of hydrodynamic stimuli. J. Fish Biol. 95, $53-72$.

Montgomery, J. C. (1989). Lateral line detection of planktonic prey. In The Mechanosensory Lateral Line (ed. Coombs, S., Görner, P., and Münz, H.), pp. 561-574. New York, NY: Springer.

Montgomery, J. C. and Macdonald, J. A. (1987). Sensory tuning of lateral line receptors in antarctic fish to the movements of planktonic prey. Science 235, 195-196.

Montgomery, J. C., Baker, C. F. and Carton, A. G. (1997). The lateral line can mediate rheotaxis in fish. Nature 389, 960-963.

Mukai, Y., Tuzan, A. D., Shaleh, S. R. M. and Senoo, S. (2006). Development of sensory organs in larvae of mouse grouper, Cromileptes altivelis. Proceeding Int. Conf. Coast. Oceanogr. Sustain. Mar. Aquac. 169-177.

Mukai, Y., Tuzan, A. D., Shaleh, S. R. M. and Manjaji-Matsumoto, B. M. (2010). Development of sensory organs and changes of behavior in larvae of the sutchi catfish, Pangasianodon hypophthalmus. Fish. Sci. 76, 921-930.

Murakami, S. L., Cunningham, L. L., Werner, L. A., Bauer, E., Pujol, R., Raible, D. W. and Rubel, E. W. (2003). Developmental differences in susceptibility to neomycininduced hair cell death in the lateral line neuromasts of zebrafish (Danio rerio). Hear. Res. 186, 47-56.

Noguera, J. C. and Velando, A. (2019). Bird embryos perceive vibratory cues of predation risk from clutch mates. Nat. Ecol. Evol. 3, 1225-1232.

Oberst, S., Bann, G., Lai, J. C. S. and Evans, T. A. (2017). Cryptic termites avoid predatory ants by eavesdropping on vibrational cues from their footsteps. Ecol. Lett. 20, 212-221.

\section{O'Brien, G. S., Rieger, S., Wang, F., Smolen, G. A., Gonzalez, R. E., Buchanan, J. and} Sagasti, A. (2012). Coordinate development of skin cells and cutaneous sensory axons in zebrafish. J. Comp. Neurol. 520, 816-831.

Otsuka, M. and Nagai, S. (1997). Neuromast formation in the prehatching embryos of the cod fish, Gadus macrocephalus Tilesius. Zoolog. Sci. 14, 475-481.

Partridge, B. L. and Pitcher, T. J. (1980). The sensory basis of fish schools: Relative roles of lateral line and vision. J. Comp. Physiol. 135, 315-325.

Pfannenstiel, R. S., Hunt, R. E. and Yeargan, K. V. (1995). Orientation of a hemipteran predator to vibrations produced by feeding caterpillars. J. Insect Behav. 8, 1-9.

Pohlmann, K., Atema, J. and Breithaupt, T. (2004). The importance of the lateral line in nocturnal predation of piscivorous catfish. J. Exp. Biol. 207, 2971-2978. 
Poo, S. and Bickford, D. P. (2014). Hatching plasticity in a Southeast Asian tree frog. Behav. Ecol. Sociobiol. 68, 1733-1740.

Roberts, D. M. (2001). Egg hatching of mosquitoes Aedes caspius and Ae. vittatus stimulated by water vibrations. Med. Vet. Entomol. 15, 215-218.

Roberts, D. M. (2018). Predator feeding vibrations encourage mosquito larvae to shorten their development and so become smaller adults. Ecol. Entomol. 43, 534-537.

Roberts, W. M., Howard, J. and Hudspeth, A. J. (1988). Hair cells: transduction, tuning, and transmission in the inner ear. Annu. Rev. Cell Biol. 4, 63-92.

Roberts, A., Feetham, B., Pajak, M. and Teare, T. (2009). Responses of hatchling Xenopus tadpoles to water currents: first function of lateral line receptors without cupulae. J. Exp. Biol. 212, 914-921.

Rogge, J. R. and Warkentin, K. M. (2008). External gills and adaptive embryo behavior facilitate synchronous development and hatching plasticity under respiratory constraint. $J$ Exp Biol 211, 3627-35.

Sand, O., Ozawa, S. and Hagiwara, S. (1975). Electrical and mechanical stimulation of hair cells in the mudpuppy. J. Comp. Physiol. 102, 13-26.

Schneider, C. A., Rasband, W. S. and Eliceiri, K. W. (2012). NIH Image to ImageJ: 25 years of image analysis. Nat. Methods 9, 671-5.

Schwalbe, M. A. B., Bassett, D. K. and Webb, J. F. (2012). Feeding in the dark: lateral-linemediated prey detection in the peacock cichlid Aulonocara stuartgranti. J. Exp. Biol. 215, 2060-2071.

Shelton, P. M. J. (1970). The lateral line system at metamorphosis in Xenopus laevis (Daudin). Development 24, 511-524.

Sih, A. and Moore, R. D. (1993). Delayed hatching of salamander eggs in response to enhanced larval predation risk. Am. Nat. 142, 947-960.

Simmons, A. M., Costa, L. M. and Gerstein, H. B. (2004). Lateral line-mediated rheotactic behavior in tadpoles of the African clawed frog (Xenopus laevis). J. Comp. Physiol. A Neuroethol. Sens. Neural. Behav. Physiol. 190, 747-758.

Smith, G. R. and Fortune, D. T. (2009). Hatching plasticity of wood frog (Rana sylvatica) eggs in response to mosquitofish (Gambusia affinis) cues. Herpetol. Conserv. Biol. 4,.

Smith, S. C., Lannoo, M. J. and Armstrong, J. B. (1988). Lateral-line neuromast development in Ambystoma mexicanum and a comparison with Rana pipiens. J. Morphol. 198, 367379. 
Song, J., Yan, H. Y. and Popper, A. N. (1995). Damage and recovery of hair cells in fish canal (but not superficial) neuromasts after gentamicin exposure. Hear. Res. 91, 63-71.

Thomas, E. D., Cruz, I. A., Hailey, D. W. and Raible, D. W. (2015). There and back again: development and regeneration of the zebrafish lateral line system. Wiley Interdiscip Rev Dev Biol 4, 1-16.

Touchon, J. C., Urbina, J. and Warkentin, K. M. (2011). Habitat-specific constraints on induced hatching in a treefrog with reproductive mode plasticity. Behav. Ecol. 22, 169175.

Van Buskirk, J. (2016). A meta-analysis on facultative responses of embryonic amphibians to predation risk. Copeia 104, 691-696.

Van Netten, S. M. (2006). Hydrodynamic detection by cupulae in a lateral line canal: functional relations between physics and physiology. Biol. Cybern. Heidelb. 94, 67-85.

Van Trump, W. J., Coombs, S., Duncan, K. and McHenry, M. J. (2010). Gentamicin is ototoxic to all hair cells in the fish lateral line system. Hear. Res. 261, 42-50.

Wang, Y., Lutfi, Z., Dong, L., Suman, D. S., Sanad, M. and Gaugler, R. (2012). Host cues induce egg hatching and pre-parasitic foraging behaviour in the mosquito parasitic nematode, Strelkovimermis spiculatus. Int. J. Parasitol. 42, 881-886.

Warkentin, K. M. (1995). Adaptive plasticity in hatching age: a response to predation risk trade-offs. Proc. Natl. Acad. Sci. U. S. A. 92, 3507-3510.

Warkentin, K. M. (2000). Wasp predation and wasp-induced hatching of red-eyed treefrog eggs. Anim. Behav. 60, 503-510.

Warkentin, K. M. (2002). Hatching timing, oxygen availability, and external gill regression in the treefrog, Agalychnis callidryas. Physiol. Biochem. Zool. 75, 155-164.

Warkentin, K. M. (2005). How do embryos assess risk? Vibrational cues in predator-induced hatching of red-eyed treefrogs. Anim. Behav. 70, 59-71.

Warkentin, K. M. (2011a). Environmentally cued hatching across taxa: embryos respond to risk and opportunity. Integr. Comp. Biol. 51, 14-25.

Warkentin, K. M. (2011b). Plasticity of hatching in amphibians: evolution, trade-offs, cues and mechanisms. Integr. Comp. Biol. 51, 111-127.

Warkentin, K. (2017). Development of red-eyed treefrog embryos: a staging table for integrative research on environmentally cued hatching. Integr. Comp. Biol. 57, E175.

Warkentin, K. M. and Caldwell, M. S. (2009). Assessing risk: embryos, information, and escape hatching. (ed. Dukas, R. and Ratcliffe, J. M.) University of Chicago Press. 
Warkentin, K. M., Jung, J. and McDaniel, J. G. (In press). Research approaches in mechanosensory-cued hatching and the iterative development of playback methods for red-eyed treefrog embryos. In Biotremology: Physiology, Ecology, and Evolution (ed. Hill, P. S. M., Mazzoni, V., Stritih Peljhan, N., Virant-Doberlet, M., and Wessel, A.), p. Springer Nature.

Warkentin, K. M., Currie, C. R. and Rehner, S. A. (2001). Egg-killing fungus induces early hatching of red-eyed treefrog eggs. Ecology 82, 2860-2869.

Warkentin, K. M., Buckley, C. R. and Metcalf, K. A. (2006a). Development of red-eyed treefrog eggs affects efficiency and choices of egg-foraging wasps. Anim. Behav. 71, $417-425$.

Warkentin, K. M., Caldwell, M. S. and McDaniel, J. G. (2006b). Temporal pattern cues in vibrational risk assessment by embryos of the red-eyed treefrog, Agalychnis callidryas. J. Exp. Biol. 209, 1376-1384.

Warkentin, K. M., Cuccaro Diaz, J., Güell, B. A., Jung, J., Kim, S. J. and Cohen, K. L. (2017). Developmental onset of escape-hatching responses in red-eyed treefrogs depends on cue type. Anim. Behav. 129, 103-112.

Warkentin, K. M., Jung, J., Rueda Solano, L. A. and McDaniel, J. G. (2019). Ontogeny of escape-hatching decisions: vibrational cue use changes as predicted from costs of sampling and false alarms. Behav. Ecol. Sociobiol. 73, 51.

Webb, J. F. and Shirey, J. E. (2003). Postembryonic development of the cranial lateral line canals and neuromasts in zebrafish. Dev. Dyn. 228, 370-385.

Whittington, I. D. and Kearn, G. C. (1988). Rapid hatching of mechanically-disturbed eggs of the monogenean gill parasite Diclidophora luscae, with observations on sedimentation of egg bundles. Int. J. Parasitol. 18, 847-852.

Whittington, I. D. and Kearn, G. C. (2011). Hatching strategies in monogenean (Platyhelminth) parasites that facilitate host infection. Integr. Comp. Biol. 51, 91-99.

Williams, J. A. and Holder, N. (2000). Cell turnover in neuromasts of zebrafish larvae. Hear. Res. 143, 171-181.

Winklbauer, R. (1989). Development of the lateral line system in Xenopus. Prog. Neurobiol. 32, 181-206.

Yan, H. Y., Saidel, W. M., Chang, J. S., Presson, J. C., Popper, A. N. and Nicol, J. A. C. (1991). Sensory hair cells of a fish ear: evidence of multiple types based on ototoxicity sensitivity. Proc. R. Soc. Lond. B Biol. Sci. 245, 133-138. 